\title{
Procedures for Determining the Performance of Stand-Alone Photovoltaic Systems
}

P. McNutt, B. Kroposki, R. Hansen, and R. DeBlasio National Renewable Energy Laboratory

M. Thomas

Sandia National Laboratories

S. Durand

Florida Solar Energy Center

A. Rosenthal

Southwest Technology Development Institute

P. Hutchinson

Photovoltaics for Utility Scale Applications

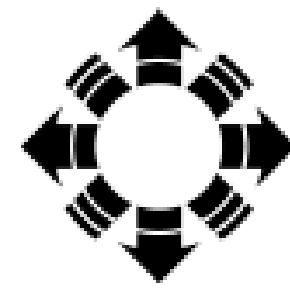

NREI

National Renewable Energy Laboratory

1617 Cole Boulevard

Golden, Colorado 80401-3393

NREL is a U.S. Department of Energy Laboratory

Operated by Midwest Research Institute $\bullet$ Battelle $\bullet$ Bechtel

Contract No. DE-AC36-98-G010337 
September 1999 - NREL/TP-520-27031

\section{Procedures for Determining the Performance of Stand-Alone Photovoltaic Systems}

P. McNutt, B. Kroposki, R. Hansen, and R. DeBlasio National Renewable Energy Laboratory

M. Thomas

Sandia National Laboratories

S. Durand

Florida Solar Energy Center

A. Rosenthal

Southwest Technology Development Institute

P. Hutchinson

Photovoltaics for Utility Scale Applications

Prepared under Task No. PV907301

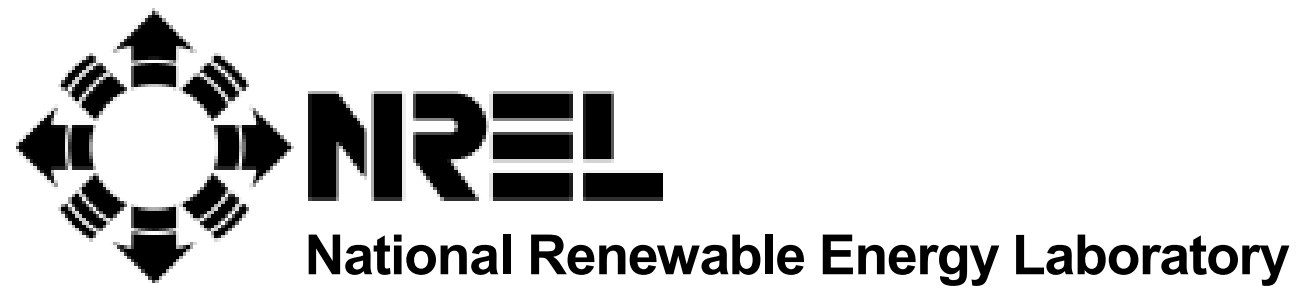

1617 Cole Boulevard

Golden, Colorado 80401-3393

NREL is a U.S. Department of Energy Laboratory

Operated by Midwest Research Institute $\bullet$ Battelle $\bullet$ Bechtel

Contract No. DE-AC36-98-G010337 


\section{NOTICE}

This report was prepared as an account of work sponsored by an agency of the United States government. Neither the United States government nor any agency thereof, nor any of their employees, makes any warranty, express or implied, or assumes any legal liability or responsibility for the accuracy, completeness, or usefulness of any information, apparatus, product, or process disclosed, or represents that its use would not infringe privately owned rights. Reference herein to any specific commercial product, process, or service by trade name, trademark, manufacturer, or otherwise does not necessarily constitute or imply its endorsement, recommendation, or favoring by the United States government or any agency thereof. The views and opinions of authors expressed herein do not necessarily state or reflect those of the United States government or any agency thereof.

Available to DOE and DOE contractors from:

Office of Scientific and Technical Information (OSTI)

P.O. Box 62

Oak Ridge, TN 37831

Prices available by calling 423-576-8401

Available to the public from:

National Technical Information Service (NTIS)

U.S. Department of Commerce

5285 Port Royal Road

Springfield, VA 22161

$703-605-6000$ or $800-553-6847$

or

DOE Information Bridge

http://www.doe.gov/bridge/home.html

Printed on paper containing at least $50 \%$ wastepaper, including $20 \%$ postconsumer waste 


\section{Table of Contents}

Section

Page

1.0 Overview

1.1 Scope

1.2 Purpose

1.3 Limitations

$\begin{array}{ll}2.0 \text { Background } & 1\end{array}$

$\begin{array}{lr}\text { 3.0 Definitions } & 2\end{array}$

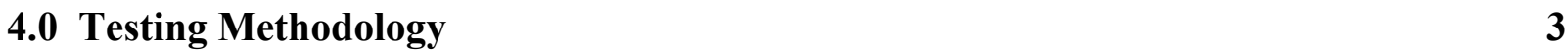

4.1 Overview

4.2 Instrumentation and Equipment 3

4.2.1 Data Acquisition System (DAS) Specifications 3

4.2.2 Sensor Specifications $\quad 3$

4.3 Test Specimen $\quad 4$

4.4 Test Documentation $\quad 4$

4.5 Test Sequence $\quad 5$

5.0 System Inspection and Test Procedures $\quad 6$

5.1 Documentation Review $\quad 6$

5.1.1 Included Documentation $\quad 6$

5.1.2 Review Documentation 6

5.1.3 Review System Operation Specifications $\quad 6$

$\begin{array}{ll}\text { 5.1.4 Review System Performance Specifications } & 6\end{array}$

5.1.5 Review System and Component Specifications 7

5.1.5.1 Load Information $\quad 7$

5.1.5.2 PV Array

5.1.5.3 Controller $\quad 7$

5.1.5.4 Battery 7

5.2 Preliminary System Inspection $\quad 8$

5.2.1 Inspect Shipping Containers $\quad 8$

5.2.2 Inspect Contents $\quad 8$

5.2.3 Array Wind Loading $\quad 8$

5.2.4 Battery Temperature Extremes Minimized 8

5.2.5 Battery Enclosure Ventilated $\quad 8$

5.2.6 Enclosures Rain and Insect Resistant $\quad 8$

5.2.7 Array Shields $\quad 8$

5.2.8 Inventory System Components 9

5.2.9 Potential System Operation Hazards 9 
$\begin{array}{ll}5.3 \text { System Installation and Instrumentation } & 10\end{array}$

$\begin{array}{ll}\text { 5.3.1 System Installation } & 10\end{array}$

5.3.2 Battery Preconditioning 10

$\begin{array}{ll}\text { 5.3.3 Verify Load Operation } & 10\end{array}$

$\begin{array}{ll}5.3 .4 \text { Installation Notes } & 10\end{array}$

5.3.5 DAS Installation $\quad 11$

$\begin{array}{ll}\text { 5.3.6 DAS Calibration } & 11\end{array}$

5.3.7 System Photograph 11

5.4 System Functional Test 12

5.4.1 System Functional Test: Average A:L Ratio 12

5.4.1.1 Load Operation Data 12

5.4.1.2 Controller Operation Data 12

5.4.1.3 Battery Operation Data 12

5.4.2 System Functional Test: Minimum A:L Ratio 13

5.4.3 Compute Hours of Operation per Sun-Hour 13

5.4.4 Other Notes 13

5.5 System Autonomy Test 14

5.5.1 Battery Charge Cycle 14

$\begin{array}{lll}\text { 5.5.1.1 Prepare System } & 14\end{array}$

$\begin{array}{ll}\text { 5.5.1.2 Charge Battery } & 14\end{array}$

5.5.1.3 Record System Data 14

5.5.2 Battery Discharge Cycle 15

$\begin{array}{ll}\text { 5.5.2.1 Prepare System } & 15\end{array}$

$\begin{array}{ll}\text { 5.5.2.2 Discharge Battery } & 15\end{array}$

5.5.2.3 Allow System To Remain In LVD State 15

5.5.2.4 Record Battery Data 15

5.5.2.5 Compute Temperature-Corrected Battery Capacity (TCBC) 15

$\begin{array}{ll}\text { 5.5.3 Compute Days of Autonomy } & 15\end{array}$

$\begin{array}{ll}5.6 \text { Recovery Test } & 16\end{array}$

5.6.1 Prepare System 16

5.6.2 Determine Load Run-Time 16

$\begin{array}{ll}\text { 5.6.3 Operate System } & 16\end{array}$

5.6.4 Determine Days to Battery Recovery 17

5.6.4.1 Calculate Daily Net-Battery Charge (DNBC) 17

5.6.4.2 Determine Daily Cumulative Solar Insolation (DCSI) 17

5.6.4.3 Plot DNBC versus DCSI 17

5.6.4.4 Determine Daily Estimated Battery Charge (DEBC) 17

5.6.4.5 Determine Days to Battery Recovery 17

$\begin{array}{ll}5.7 \text { System Maintenance Procedure Review } & 18\end{array}$

5.8 Final System Inspection 18

$\begin{array}{ll}5.8 .1 \text { Visual Inspection } & 18\end{array}$

$\begin{array}{ll}\text { 5.8.2 Wiring Inspection } & 18\end{array}$

$\begin{array}{ll}\text { 5.8.3 End Date } & 18\end{array}$ 
$\begin{array}{lr}\text { 6.0 Array I-V Curve } & 18\end{array}$

$\begin{array}{ll}7.0 \text { Load Performance Test (Optional) } & 18\end{array}$

$\begin{array}{lr}\text { 8.0 References } & 19\end{array}$

$\begin{array}{ll}\text { Annex A. Sample System Summary } & \text { A1 }\end{array}$

Annex B. Description of System Summary Terms and Parameters B1

List of Figures

Figure 4-1. Stand-Alone PV Systems Test Sequence. 5 


\subsection{Overview}

\subsection{Scope}

The procedures in this document cover small stand-alone PV systems. They cover complete outdoor system testing. Test results are valid only for the system that is tested.

\subsection{Purpose}

This document provides the procedures for determining the performance of stand-alone PV systems. The procedures in this document provide a common approach for evaluating whether a given PV system is suitable to perform the function for which it was designed and manufactured to accomplish, and whether it will provide adequate power to run the load.

\subsection{Limitations}

The focus of the procedures in this document will be limited to complete system performance evaluations only. Individual subsystems and components may be monitored, but only to evaluate the performance of the overall system.

These procedures do not address component or system reliability, quality issues, safety, or compliance to a regional or national mechanical or electrical code (e.g., NEC). These procedures do not cover grid-tied or PV-hybrid systems. These procedures have been validated on PV systems with non-motorized loads and battery storage. Future procedures will be written and validated to test a wider variety of PV systems and loads.

Although some of the tests found in these procedures are non-standard, particularly regarding the battery testing, their results will better determine the operation of PV systems installed in the field.

\subsection{Background}

Selection and validation, through type testing, of the appropriate design and construction of a PV system and its subsystems is a critical area of concern with regard to meeting and optimizing performance, operation and maintenance (O\&M), reliability, and safety. Over- or undersizing a system, inadequate subsystem and component selections, and improper interface matching have been concerns over the years with regard to meeting performance requirements and cost. System failures caused by exceeding the operational limits of subsystems and components within the system has led to misunderstandings regarding why the system did not meet its application load requirements. Exaggerated performance expectations and marginal design limits have also led to failure in parts of the system and have increased system O\&M costs. Users must feel assured that a system will meet its intended design and application load requirements. This barrier to acceptance of PV systems by users can be reduced and eliminated if they are provided with the proper tools to reference for design and performance verification.

This test document fills a testing void and provides the catalyst and focus for establishing the technical foundation and bridging the institutional barriers needed to reduce uncertainty that a system's performance will be what its designers and builders claim. The need for this document was recently made more apparent with the initiation of a PV Global Approval Program at the international level. It is in response to concerns that PV systems in the field must meet performance standards and that these standards include system-level performance type tests. The Institute of Electrical and Electronic Engineers Standards Coordinating Committee 21 (IEEE SCC21) and the International Electrotechnical Commission Technical Committee 82 (IEC TC82), which are national and international standards-making bodies, have initiated projects to develop test standards and will need the technical basis and validation of test procedures before a consensus is achieved by the PV community. This document will serve as the basis for national and international stand-alone PV system test standards. 


\subsection{Definitions}

These terms are defined as they are used in this document $[1,4,10]$.

Battery - A chemical device that stores electrical energy. A battery may be composed of multiple batteries or cells.

Charge Controller - A device that protects the battery from overcharge. The charge controller may also monitor the system performance and provide system protection, such as protecting the battery from over discharge.

Cumulative Solar Insolation - The summation of the measured solar irradiance over a giver period of time.

Days of Autonomy - The number of days that a fully charged battery can satisfy the load with no contribution from the PV array.

Design Month - The month in which the daily ratio of the energy generated by the array to the energy consumed by the load is minimum. This may not necessarily be the month with the minimum number of sun-hours.

Load - A device connected to an electrical system that consumes electrical power. Systems may have multiple loads. Some loads may have built-in battery low-voltage disconnect protection.

Low Voltage Disconnect (LVD) Set Point - The voltage set point at which the load is disconnected from the battery to prevent over discharge of the battery.

Open-Circuit Voltage $\left(\mathbf{V}_{\mathbf{o c}}\right)$ - The voltage at the output terminals of a device when no current is flowing in a circuit.

Plane-of-Array (POA) Irradiance - The solar energy measured in the same plane as the PV array.

Rated Capacity - The amp-hours a fully charged battery is specified to deliver at a specified battery temperature and discharge rate, to a specified cutoff voltage.

Regulation Voltage - The maximum voltage point that the charge controller will allow the battery to reach under charging conditions. At this point, the charge controller will reduce or remove the array energy from the battery.

Short-Circuit Current ( $\left.\mathbf{I}_{\text {sc }}\right)$ - The current flowing between the shorted terminals of a PV device.

Standard Test Conditions (STC) - The accepted conditions under which PV devices are commonly rated: $1000 \mathrm{~W} / \mathrm{m}^{2}$ irradiance at a spectral distribution of AM 1.5 and a $25^{\circ} \mathrm{C} \mathrm{PV}$ cell temperature.

Sun-Hours - The equivalent number of hours of peak $\left(1000 \mathrm{~W} / \mathrm{m}^{2}\right)$ sunlight received per day at a particular location in the plane of the array. Value for various locations and times of the year can be found in references [5] and [8].

$$
\text { Sun Hours }=\left(\text { Total Sunlight }\left(\mathrm{Wh} / \mathrm{m}^{2}\right) \text { per Day }\right) / 1000 \mathrm{~W} / \mathrm{m}^{2} \text {. }
$$

Temperature-Corrected Battery Capacity (TCBC) - The temperature-corrected amp-hours a fully charged battery will deliver to the system load before reaching the LVD cutoff voltage.

Usable Battery Capacity (UBC) - The measured amp-hours, before temperature-correction, that a fully charged battery will deliver to the system load before reaching the LVD cutoff voltage. 


\subsection{Testing Methodology}

\subsection{Overview}

These procedures will test PV systems for overall system functionality. The necessary instrumentation to perform the testing is described in Section 4.2. The test specimens are described in Section 4.3. Section 4.4 describes the documentation that will be generated and kept from the testing. The test-sequence flow chart is provided in Section 4.5. Within the flow chart, there are specific tests that are then described in Section 5.0. A sample System Summary is provided in Annex A. The Tester shall fill in as much of the requested System Summary data as possible. Annex B provides a brief description of the terms and parameters found in the System Summary. The specific sequence of tests to be run will be determined based on the specific system to be tested and its loads. Examples of different types of PV systems are described in references [3 - 5].

\subsection{Instrumentation and Equipment}

The following instrumentation and equipment is necessary for conducting the system tests:

\subsubsection{Data Acquisition System (DAS) Specifications}

The datalogger shall use at least a 12 bit analog-to-digital converter and have an input range that exceeds the expected positive and negative maximum voltages. The DAS must be reliable: if more than 4 hours worth of data is lost due to a power failure during any test, then that test shall be restarted.

The sample rate of the datalogger is dependent on the type of charge controller. For ON-OFF controllers, the datalogger sample rate shall be at least two times faster than the switching period of the controller. As an example, if the operation of the regulation voltage circuitry is every 10 seconds, then the sample rate shall be once every 5 seconds, or faster.

For charge controllers using constant-voltage or pulse-width-modulation circuitry, the switching period may be milliseconds, not seconds. Some dataloggers can not sample that quickly. If the datalogger sample rate is not fast enough, then one method is to sample once per second with an integrator/filter circuit added to the DAS input. The time constant of the integrator/filter will need to be at least two times the sample period.

An oscilloscope may be required to determine the controller type and its switching frequency.

Data shall be stored as 15 minute averages with minimums and maximums as appropriate for each test.

\subsubsection{Sensor Specifications}

The voltage sensors shall have a range exceeding the maximum expected voltage and a resolution of at least $0.01 \mathrm{~V}$. The voltage sensor accuracy shall be at least $+/-0.1 \mathrm{~V}$.

The current sensors shall have a range exceeding the expected maximum positive and negative current and a resolution of at least $0.01 \mathrm{~A}$.

The current sensor accuracy shall be at least $+/-0.1 \mathrm{~A}$.

The temperature sensors shall have a range exceeding the expected maximum positive and negative system and ambient temperatures and a resolution of at least $1^{\circ} \mathrm{C}$.

The temperature sensor accuracy shall be at least $+/-2^{\circ} \mathrm{C}$.

The irradiance sensor shall have a range of at least $1500 \mathrm{~W} / \mathrm{m}^{2}$ and a resolution of at least $1.0 \mathrm{~W} / \mathrm{m}^{2}$.

The irradiance sensor accuracy shall be at least $+/-5 \%$ of the reading. 


\subsection{Test Specimen}

At least one complete system representative of the systems to be deployed in the field is required to conduct the tests in this document.

A complete system will include documentation and all related parts for installation.

Spare parts may be included in the event parts are damaged in shipment or during testing.

The following shall be specified, or agreed upon before testing begins:

- The load

- The load hours of operation

- The intended location where the system will installed and operated (not necessarily the test location).

If optional PV system meters or indicators are available, these shall also be procured with the system.

\subsection{Test Documentation}

In addition to filling in the System Summary, the Tester shall keep relevant test data, calculations, and appropriate comments. An electronic copy of the system data shall be kept for future reference. 


\subsection{Test Sequence}

The large text in each box is the title of the corresponding test in the procedures. Small text represents an important system parameter that is found in that procedure. The corresponding procedure number is found in parentheses.

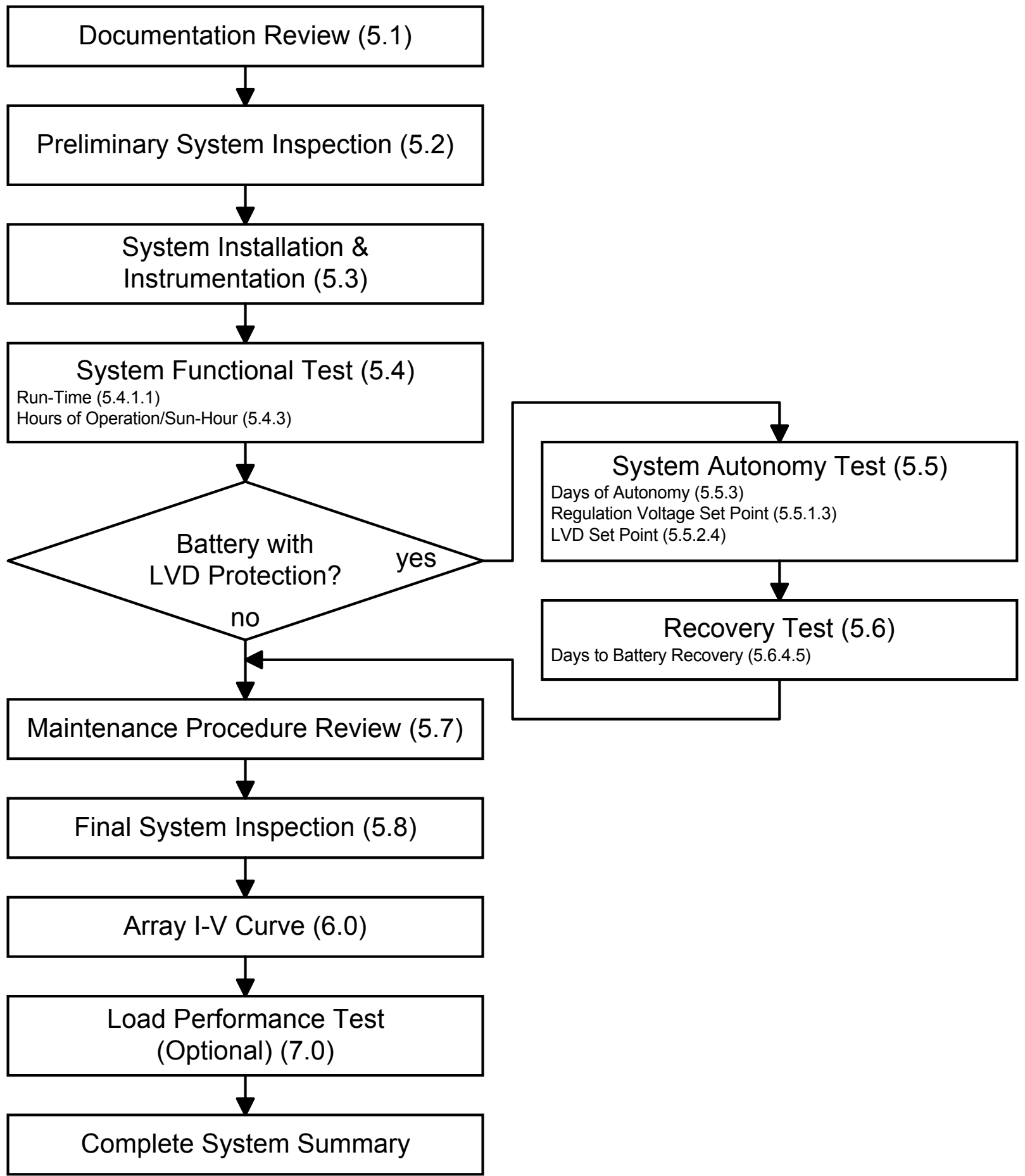

Figure 4-1. Stand-Alone PV Systems Test Sequence. 


\subsection{System Inspection and Test Procedures}

In this section, not all of the following procedures and steps will apply to all systems. The actual tests to be run will be determined based on the specific system to be tested and its load(s).

\subsection{Documentation Review}

Copy all documentation received with the system and include it with the System Summary. The documentation may include the following items:

\subsubsection{Included Documentation}

In the System Summary check off all documentation included with the system:

- Parts List

- Required-but-Not-Included Parts List

- Recommended Tool List

- Mechanical Drawings

- Electrical Schematics

- Installation Procedures

- Spare-Parts List

- Maintenance Procedures

- Troubleshooting Guide

- Component-Specification Literature.

\subsubsection{Review Documentation}

Read all documentation to verify it is clear and relevant to installing and operating the system.

Note whether all steps can be performed by one or two people with the required equipment.

Fill in as much as possible of the Test Information section of the System Summary.

Fill in the System Information section of the System Summary.

Fill in as much as possible of the Mechanical Design Information section of the System Summary.

\subsubsection{Review System Operation Specifications}

Fill in the System Operation section of the System Summary.

Record the system manufacturer's recommended range of run-times for the load.

Record how the load is controlled.

Record in the System Operation section of the System Summary the location for which the system is intended (not necessarily the test location).

\subsubsection{Review System Performance Specifications}

If provided by the system manufacturer, fill in the requested System Performance parameters:

- Hours of Operation per Sun-Hour

- Days of Autonomy

- Days to Battery Recovery. 


\subsubsection{Review System and Component Specifications}

Record the specifications for the system and each component in the appropriate section of the System Summary. If the system includes an inverter, it will be considered part of the DC load.

The system specifications may include the following for each applicable component:

\subsubsection{Load Information:}

- Description

- Manufacturer

- Voltage

- Current

- Power

- Operating Temperature Range

- Life Expectancy

- Number of Loads.

\subsubsection{PV Array:}

- Module Manufacturer

- Module Model

- Active Material

- Array Configuration

- Array Maximum Power @ STC

- Array $V_{p p}$

- Array $I_{p p}$

- Array $\mathrm{V}_{\mathrm{oc}}$

- Array $\mathrm{I}_{\mathrm{sc}}$

- Array Shield.

5.1.5.3 Controller:

- Manufacturer

- Model

- Description

- Regulation Voltage

- Controller-Battery Compatibility

- Temperature Compensation Sensor Attaches to Battery

- Reverse-Current Protection

- Load Timer Accuracy

- Low-Voltage Disconnect.

5.1.5.4 Battery:

- Manufacturer

- Model

- Type

- Configuration

- Voltage

- Capacity. 


\subsection{Preliminary System Inspection}

\subsubsection{Inspect Shipping Containers}

Record in the System Summary the date that the system arrived at the test facility. This will be the Start Test Date.

Note if any of the parcels are damaged.

Note if any parcel requires more than two people to move.

Note if the battery container has the potential to spill electrolyte.

\subsubsection{Inspect Contents}

Record the weight of the load and its mounting structure.

Record the weight of the PV array, the mounting structure, and the array shield.

Record the weight of the entire battery bank and the battery enclosure.

Visually inspect system parts and components and verify that they arrived undamaged.

Note any damage.

If damage is found, determine if the damage was due to inadequate packaging.

Replace any damaged items.

\subsubsection{Array Wind Loading}

Calculate the wind loading equivalent to 120 -mph winds upon the array. Multiply the horizontal cross-sectional area of the array by 37.0 pounds per square foot. The horizontal cross sectional area is calculated as the PV array area times the sine of the array tilt angle. This information can be helpful in determining if the fasteners are sufficient to connect the array to the pole. One can also determine if the pole can withstand the bending moment [9]. If several tilts are possible, a $45^{\circ}$ tilt angle shall be used for calculations.

\subsubsection{Battery Temperature Extremes Minimized}

Note if the system design minimizes battery temperature extremes.

Lead-acid battery capacity decreases as the battery temperature decreases $[6,7,10]$.

Burying the enclosure underground is one method of regulating battery temperature.

\subsubsection{Battery Enclosure Ventilation}

Note if the system design allows for proper battery ventilation.

Ventilation is important to avoid the buildup of explosive gases that are generated while the battery is charged.

\subsubsection{Enclosures Rain and Insect Resistant}

Note if all enclosure openings prevent water and insects from entering.

\subsubsection{Array Shields}

Note if there is a back or front shield on the array. If there is, note the material used, and its placement with respect to the array.

An array shield might be mounted on the modules to protect them from vandalism.

A front shield can substantially reduce the power output of the array.

A solid back shield may cause the array power output to decrease by increasing the array operating temperature. 


\subsubsection{Inventory System Components}

Verify that all parts listed in the Parts List are present.

Note any missing system parts that should have been included but were not.

Any parts that are required, but not supplied with the system, should be procured at this point.

These should be listed in the Required-but-Not-Included Parts List.

The Tester shall not modify or add to the system: the system shall only be installed and tested as it is received and as specified in the documentation.

\subsubsection{Potential System Operation Hazards}

The Tester may refuse to test a system that could be dangerous to operate. 


\subsection{System Installation and Instrumentation}

\subsubsection{System Installation}

Install the system according to the manufacturer's instructions.

Depending upon the system configuration, it may be easier to install the DAS during the system assembly.

The installation instructions should cover all steps of the system assembly.

The Tester shall not modify or add to the system: the system shall only be installed and tested as it is received and as specified in the documentation.

If cabling is precut for system installation, the Tester shall use the full length of cable received with the system.

Caution should be used in installing the charge controller, as some need to be connected in a specified sequence to avoid damage. Consult the manufacturer's instructions.

\subsubsection{Battery Preconditioning}

If the battery is received dry, follow the manufacturer's instructions for adding electrolyte and preconditioning the battery for system operation.

If battery preconditioning is not called for in the system documentation, the system shall only be installed and operated as explained in the manufacturer's instructions. Note this.

\subsubsection{Verify Load Operation}

Verify that the load starts and operates properly.

In systems with multiple loads, verify that each individual load can start and run while all other loads are operating. For this test, it is only necessary to operate the loads long enough to determine if they function correctly.

For example, run a low-pressure sodium lamp until it reaches full brightness, usually about 15 minutes.

Turn off all loads after verifying they operate properly.

\subsubsection{Installation Notes}

Note any missing steps or difficulties in following the manufacturer-supplied installation procedures.

Record the installation time in Person-Hours. 


\subsubsection{DAS Installation}

Install the POA irradiance sensor.

The irradiance sensor shall be as close as possible to the array without shading the array.

The irradiance sensor shall be mounted in the same plane and within $+/-5^{\circ}$ of the array tilt angle.

Program the DAS to monitor the irradiance and store as 15 minute averages.

Install the temperature sensors:

- The ambient temperature sensor should be mounted in an aspirated shield.

- The temperature sensor on the back of the module should be mounted in the middle of a solar cell within the center of a module.

- The battery temperature sensor should be mounted as close as possible to the temperature compensation sensor. If temperature compensation is internal to the charge controller, a temperature sensor in addition to the battery temperature sensor shall be mounted to sense the controller temperature.

Program the DAS to monitor the temperatures and store as 15 minute averages.

Install voltage sensors for the PV array and loads.

Program the DAS to monitor the array and load voltages and store as 15 minute averages.

Install the voltage sensor for the battery at the battery terminals.

Program the DAS to monitor the battery voltage and store as 15 minute averages.

Maximums and minimums shall also be collected and stored.

Install current sensors for the PV array, battery, and loads.

Program the DAS to monitor the current into and out of the battery, and store as 15 minute averages.

Amp-hours shall be computed by multiplying the DC current and unit-time.

Calculate array and load DC Power. DC power shall be computed by multiplying average DC voltage and average DC current.

Install a sensor to detect proper load operation, for example, a light sensor mounted in front of the lamp.

Program the DAS to monitor the load elapsed time and store the load operation data as 15 minute averages.

Modify a copy of the schematic to show the DAS sensor locations.

This modified schematic shall be included with the System Summary.

\subsubsection{DAS Calibration}

After the DAS installation, verify the calibration of each sensor.

Note the type and accuracy of each sensor.

Note the calibration factor, and the date of the last calibration, of each sensor, if applicable.

\subsubsection{System Photograph}

Photograph the PV system and load after the system has been installed and instrumented.

Include the photo with the System Summary. 


\subsection{System Functional Test}

The System Functional Test monitors the performance of the system as it operates under outdoor conditions. This test is divided into two parts: The first part monitors the system operating at the system design "average" daily Array-to-Load (A:L) ratio. The second part monitors the system as it operates at the system design "minimum" daily A:L ratio. Both data collection periods shall consist of at least 7 days.

\subsubsection{System Functional Test: Average A:L Ratio}

The purpose of this test is to determine the system operating parameters while operating at the system design "average" daily A:L ratio. Using the specified daily load run-time, and the annual average daily sun-hours for the location where the system is intended to be used, determine the A:L ratio for this test.

1. Compute the average daily A:L ratio for the intended location (not necessarily the test location) for each month.

2. Select or compute the average daily A:L ratio from the 12 months.

3. Using the sun-hours for the current month at the test location, calculate the Daily Run-Time required to give the desired A:L ratio.

\section{A:L Ratio $=\frac{\text { Array Current } x \text { Sun Hours }}{\text { Load Current } x \text { Daily Run }- \text { Time }}$}

where

Array Current (A) is the STC-rated array current at maximum power.

Sun-Hours (Hr/Day) is the equivalent number of hours of sunlight received per day at a particular location in the plane of the array. This information may be found in references [5] and [8].

Load Current (A) is the average current draw of the load.

Daily Run-Time (Hrs/Day) is the number of hours the load is set to operate each day as recommended by the manufacturer.

The Tester controls the A:L ratio by adjusting the Daily Run-Time.

Note the calculated A:L ratio.

Note the selected daily load run-time setting.

Operate the system at least 7 days, with at least 3 sunny days, each with greater than $3 \mathrm{kWh} / \mathrm{m}^{2}$ solar insolation.

Verify the system and load are operating as expected by reviewing the system data each day.

\subsubsection{Load Operation Data}

For the time when the load is operating, record the following in the Load Information section of the System Summary:

- Average load voltage (V)

- Average load current (A)

- Average load power (W).

Record the measured load Run-Time in the System Operation section of the System Summary.

Compute and record the Run-Time accuracy of the system load timer in the Controller Information section of the System Summary.

\subsubsection{Controller Operation Data}

Verify that all meters and indicators function correctly.

\subsubsection{Battery Operation Data}

Record the maximum and minimum battery voltages during the this test in the Battery Information section of the System Summary. 


\subsubsection{System Functional Test: Minimum A:L Ratio}

The purpose of this test is to determine how the system functions when the A:L Ratio is at the system design minimum. This will occur during the Design Month. The Hours of Operation per Sun-Hour will also be computed from this test.

Compute the daily load run-time that will achieve the minimum daily A:L ratio (see 5.4.1):

1. Compute the average daily A:L ratio for the intended location (may not necessarily be the test location) for each month.

2. Select the minimum daily A:L ratio from the 12 months. Record this month as the Design Month in the System Operation section of the System Summary.

3. Using the sun-hours for the current month at the test location, calculate the daily run-time required to give the desired A:L ratio.

Note the selected daily load run-time setting.

Operate the system at least 7 days, with at least 3 sunny days, each with greater than $3 \mathrm{kWh} / \mathrm{m}^{2}$ solar insolation.

Verify that the system and the load are operating correctly by reviewing the system data each day.

\subsubsection{Compute Hours of Operation per Sun-Hour}

Compute and record the Hours of Operation per Sun-Hour. This value indicates how many hours the load could operate each day for every sun-hour. For example, if the Hours of Operation per Sun-Hour value were 2.0, and the average number of sun-hours for a particular location during a particular month were 5.0, then we could expect that the load could run for $2.0 \times 5.0$, or 10 hours.

\section{Hours of Operation per Sun-Hour $=\frac{\text { ArrayEnergy Production }}{\text { LoadEnergyConsumption }}$,}

where

Array Energy Production (Ah) is the amp-hours received by the battery over the course of the Minimum A:L Ratio System Functional Test.

Load Energy Consumption (Ah) is the amp-hours delivered to the load over the course of the Minimum A:L Ratio System Functional Test.

\subsubsection{Other Notes}

During the System Functional Test, note any days when the load failed to operate, or if the load did not operate its entire daily run-time.

Note any unusual occurrences during the test period. These may include unplanned short or open circuits, DAS malfunctions, etc. 


\subsection{System Autonomy Test}

The system autonomy test determines how many days a fully charged battery can satisfy the system load with no contribution from the PV array [2,6,7]. This test shall only be run on systems with a battery protected by lowvoltage disconnect (LVD) circuitry.

If the battery charge and discharge set points are adjustable, use the set points recommended by the manufacturer, or if this information is not provided, use the set points as received.

\subsubsection{Battery Charge Cycle}

\subsubsection{Prepare System}

- Disable or disconnect the load

- Connect the array.

\subsubsection{Charge Battery}

Allow the array to fully charge the battery. In these procedures the battery will be considered fully charged after the charge controller reaches regulation voltage and continues to reach regulation voltage the following 3 days.

One way to determine when regulation voltage was reached, from inspecting system data, is to compare the irradiance plot to the battery charge current plot. Before reaching regulation, the "shape" of the battery charge current plot will almost exactly match the irradiance plot. After regulation is reached, the "shape" of the battery charge current "flattens out" and deviates from the irradiance plot.

Verify that all meters and indicators function correctly.

\subsubsection{Record System Data}

Record the maximum battery voltage as the Regulation Voltage Set Point in the Controller Information section of the System Summary.

Note the corresponding battery temperature, and the temperature-compensation-sensor temperature. 


\subsubsection{Battery Discharge Cycle}

\subsubsection{Prepare System}

Disconnect the array.

Connect the load.

\subsubsection{Discharge Battery}

Operate the full load continuously, 24 hours per day, until it fully discharges the battery. In this test, the battery will be defined as fully discharged when it reaches LVD.

Some systems may require special measures in order to run the load continuously down to LVD.

Verify that all meters and indicators function correctly.

\subsubsection{Allow System To Remain In LVD State}

Allow the system to remain in this LVD state for 72 hours.

Note if the controller attempts to reconnect the load to the battery during this time.

\subsubsection{Record Battery Data}

Record the minimum measured battery voltage as the LVD Set Point in the Controller Information section of the System Summary.

Note the amp-hours withdrawn from the battery. This will be designated the Usable Battery Capacity (UBC).

\subsubsection{Compute Temperature-Corrected Battery Capacity (TCBC)}

Calculate and record the usable battery capacity as a function of battery temperature if the battery temperature factor is available from the battery or system manufacturer.

\section{$\mathrm{TCBC}=(\mathrm{UBC} \times \mathrm{T}$ Temperature Factor $)$,}

where

$\underline{\mathrm{UBC}}(\mathrm{Ah})$ is the capacity of the battery measured in 5.5.2.4.

Temperature Factor is a multiplier provided by the manufacturer indicating what percentage of the rated capacity can be extracted from a fully charged battery at a given battery temperature.

If the temperature factor is not provided, use the UBC instead of the TCBC and note this.

Fill in the Measured-Capacity value in the Battery Information section of the System Summary with the value calculated here.

\subsubsection{Compute Days of Autonomy}

Compute and record the Days of Autonomy in the System Performance Results section of the System Summary. The Days of Autonomy value indicates how long the system may operate the load during periods of low irradiance.

$$
\text { Days of Autonomy }=\frac{\text { TCBC }}{\text { Load Current } x \text { Daily Run Time }} \text {, }
$$

where

TCBC $(\mathrm{Ah})$ is the temperature-corrected Ah capacity of the battery calculated in 5.5.2.5. If the Temperature Factor is not available, use the UBC (5.5.2.4) instead and note this.

Load Current (A) is the average current draw of the load measured in 5.4.1.1.

Daily Run-time (Hrs/Day) is the number of hours the load is set to operate each day as recommended by the manufacturer. 


\subsection{Recovery Test}

The purpose of the Recovery Test is to predict how many days are required for the array to charge the fully discharged battery with an "average" daily A:L ratio. This test is run for 7 days, or until the charge controller reaches regulation voltage, whichever occurs first.

\subsubsection{Prepare System}

The battery must be at LVD before starting this test.

- Note the start date and time

- Connect the array

- Connect the load.

\subsubsection{Determine Load Run-Time}

Using the specified daily load run-time, and the monthly average daily sun-hours for the intended location, use the average A:L ratio for this test (see 5.4.1).

The Tester controls the A:L ratio by adjusting the Daily Run-Time.

Note the A:L ratio.

Note the Daily Run-Time.

\subsubsection{Operate System}

Operate the system and load normally for 7 days, or until the controller reaches regulation voltage, whichever occurs

first. The load may not turn on the first few days until the battery voltage rises above the Low-Voltage Reconnect voltage set point. 


\subsubsection{Determine Days to Battery Recovery}

\subsubsection{Calculate Daily Net-Battery Charge (DNBC)}

Calculate the DNBC for each day during the Recovery Test.

Use only that portion of the charge up until regulation if the controller reaches regulation voltage before the end of the day.

\section{DNBC $=$ Daily Battery Charge - Daily Battery Discharge,}

where

Daily Battery Charge (Ah) is the total positive charge into the battery during a 24 hour day.

Daily Battery Discharge (Ah) is the total negative discharge from the battery during a 24 hour day.

\subsubsection{Determine Daily Cumulative Solar Insolation (DCSI)}

Determine the DCSI for each day during the Recovery Test. The insolation is found by summing the irradiance. Use only that portion of the insolation up until regulation, if the controller reaches regulation voltage before the end of the day.

\subsubsection{Plot DNBC vs. DCSI}

Plot the DNBC versus the DCSI during the Recovery Test.

\subsubsection{Determine Daily Estimated Battery Charge (DEBC)}

From a linear fit of the data in the plot, determine the DEBC for the insolation at the intended location on an annual average Design-Month day.

\subsubsection{Determine the Days to Battery Recovery}

Determine the Days to Battery Recovery.

$$
\text { Days to Battery Recovery }=\frac{\text { TCBC }}{\text { DEBC }},
$$

where

$\mathrm{TCBC}(\mathrm{Ah})$ is the temperature corrected usable battery capacity found in section 5.5.2.5.

$\underline{\operatorname{DEBC}(\mathrm{Ah} / \mathrm{Day})}$ is the predicted charge from the array into the battery on an average Design-Month day.

This is an estimate of how many annual average Design-Month days would be required to replace the UBC in the fully discharged battery while the load is set for normal operation.

Record the Days to Battery Recovery in the System Performance Results section of the System Summary. 


\subsection{System Maintenance Procedure Review}

Perform the manufacturer recommended maintenance procedures. Note in the System Summary if the maintenance procedures are clear and report any difficulties that occurred in performing the maintenance procedures, for example, having to disassemble and remove the battery bank in order to check battery electrolyte level.

\subsection{Final System Inspection}

\subsubsection{Visual Inspection}

Visually inspect the system, noting any problems or damage in the System Summary. The inspection should include all major system components:

- Loads

- PV Array

- Mounting structure

- Wire

- Fuses, disconnects, protection devices

- Controller

- Battery.

\subsubsection{Wiring Inspection}

Flex all conductors along their entire length, noting any discoloration or brittleness of the insulation. Undersized conductors and poor connections will tend to overheat, leading to brittle and discolored insulation.

\subsubsection{End Date}

Record the date testing ends.

\subsection{Array I-V Curve}

After the system has been operating outdoors for several weeks, an I-V curve of the array may be swept.

If the array has a front shield, sweeping an I-V curve shall be mandatory.

- Disconnect the array from the system.

- Attach an I-V curve tracer to the DC terminals of the array.

- Sweep a curve on a clear, sunny day, and when the POA irradiance is between 800 and $1100 \mathrm{~W} / \mathrm{m}^{2}$.

- Normalize the curve to $1000 \mathrm{~W} / \mathrm{m}^{2}$ and to a PV cell temperature of $25^{\circ} \mathrm{C}$.

Record the following measured array information, normalized to STC, in the Array Information section of the System Summary:

- Array Maximum Power

- Array $I_{\mathrm{sc}}$

- Array $\mathrm{V}_{\text {oc }}$

- Array $V_{\mathrm{pp}}$

- Array $\mathrm{I}_{\mathrm{pp} \text {. }}$

\subsection{Load Performance Test (Optional)}

It may be desired to run performance tests on the load(s). Such tests may be found in other documents, for example, reference [9] describes in detail how to test a PV lighting system. Such tests are beyond the scope of this document. Such tests may require specialized test equipment. 


\subsection{References}

1. The IEEE Standard Dictionary of Electrical and Electronic Terms. ANSI/IEEE Standard 100. 1992, New York, NY: The Institute of Electrical and Electronic Engineers.

2. Recommended Practice for Maintenance, Testing, and Replacement of Large Lead Storage Batteries for Generating Stations and Substations. ANSI/IEEE Standard 450. 1987, New York, NY: The Institute of Electrical and Electronic Engineers.

3. Maintenance and Operation of Stand-Alone Photovoltaic Systems. December 1991, Albuquerque, NM: Photovoltaic Design Assistance Center, Sandia National Laboratories.

4. Photovoltaic System Design. Course Manual. 1991, Cocoa, FL: Florida Solar Energy Center.

5. Stand-Alone Photovoltaic Systems: A Handbook of Recommended Design Practices. March 1995, Albuquerque, NM: Photovoltaic Design Assistance Center, Sandia National Laboratories.

6. Storage Battery Technical Service Manual. $10^{\text {th }}$ Edition. 1987, Chicago, IL: Battery Council International.

7. Perez, Richard. The Complete Battery Book. 1985, Blue Ridge Summit, PA: Tab Books.

8. Solar Radiation Data Manual for Flat-Plate and Concentrating Collectors. April 1994. NREL/TP-463-5607, Golden, CO. National Renewable Energy Laboratory.

9. “A Preliminary Evaluation of the PV Streetlight Outdoor Lighting System.” Contract Report. May 26, 1999, Cocoa, FL. Florida Solar Energy Center.

10. Guide For Selection, Test and Evaluation of Lead-Acid Batteries Used in PV Systems. ANSI/IEEE PAR 1361 Draft 6.0 Revised July 8, 1999, New York, NY: The Institute of Electrical and Electronic Engineers. 


\section{Annex A \\ (Informative)}

\section{Sample System Summary}

For each PV system tested, a System Summary shall be completed by the Tester and submitted to the Requestor. Fill in the Report Date in the Test Information section of the System Summary upon completing the Summary.

A sample Summary follows.

In general:

- Information entered in the "Specified" column is information provided by the system or component manufacturers.

- Information in the "Measured/Observed" column is information gathered, or calculated, during the system tests.

Depending upon the specific system to be tested, not all items in the Summary will have entries.

The Section number corresponds to a brief description found in Annex B for each parameter.

Annex B should be included with the System Summary to explain each entry.

The corresponding test procedure section number is listed in each entry box.

In addition to the completed System Summary, the following items shall also be provided to the Requester:

- Copies of all documentation provided with the system (5.1)

- A modified copy of the schematic to show the DAS sensor locations (5.3.5)

- A photograph of the overall system (5.3.7).

Supporting test data, along with appropriate comments, may also be attached and submitted as part of the System Summary. 


\section{Stand-Alone Photovoltaic \\ System Summary - Page 1 of 2}

\begin{tabular}{|c|c|c|c|}
\hline \multicolumn{4}{|c|}{$\begin{array}{l}\text { Parameter } \\
\end{array}$} \\
\hline $\mathrm{B} 1.1$ & Start Test Date & 5.2 .1 & \\
\hline $\mathrm{B} 1.2$ & End Test Date & 5.8 .3 & \\
\hline $\mathrm{B} 1.3$ & Report Date & & \\
\hline B1.4 & Test Facility & 5.1 .2 & \\
\hline \multirow[t]{2}{*}{ B1.5 } & Address & 5.1 .2 & \\
\hline & Address & & \\
\hline B1.6 & Contact & 5.1 .2 & \\
\hline \multicolumn{4}{|c|}{ 2) System Information } \\
\hline \multicolumn{4}{|c|}{ arameter } \\
\hline B2.1 & Manufacturer & 5.1 .2 & \\
\hline B2.2 & Model & 5.1 .2 & \\
\hline $\mathrm{B} 2.3$ & Vendor & 5.1 .2 & \\
\hline \multicolumn{4}{|c|}{ System Operation } \\
\hline \multicolumn{2}{|r|}{ Parameter } & \multirow[t]{2}{*}{ Specified } & Measured/Observed \\
\hline B2.4 & Run-Time & & 5.4 .1 .1 \\
\hline B2.5 & Load Control Method & 5.1 .3 & \\
\hline B2.6 & System Intended Location & 5.1 .3 & \\
\hline B2.7 & Intended Location Design Month & 5.1 .3 & 5.4 .2 \\
\hline \multicolumn{4}{|c|}{ System Performance Results } \\
\hline Section & Parameter & Specified & Measured/Observed \\
\hline B2.8 & Hours of Operation per Sun-Hour & 5.1 .4 & 5.4 .3 \\
\hline B2.9 & Days of Autonomy & 5.1 .4 & 5.5 .3 \\
\hline $\mathrm{B} 2.10$ & Days to Battery Recovery & 5.1 .4 & 5.6 .4 .5 \\
\hline \multicolumn{4}{|c|}{ 3) Load Information } \\
\hline \multicolumn{2}{|r|}{ Parameter } & Specified & Measured/Observed \\
\hline B3.1 & Description & 5.1 .5 .1 & \\
\hline B3.2 & Manufacturer & 5.1 .5 .1 & \\
\hline B3.3 & Voltage & 5.1.5.1 & 5.4.1.1 \\
\hline B3.4 & Current & 5.1.5.1 & 5.4.1.1 \\
\hline B3.5 & Power & 5.1.5.1 & 5.4.1.1 \\
\hline B3.6 & Operating Temperature Range & 5.1.5.1 & \\
\hline B3.7 & Number of Loads & 5.1.5.1 & \\
\hline \multicolumn{4}{|c|}{ 4) Array Information } \\
\hline Section & Parameter & Specified & Measured/Observed \\
\hline B4.1 & Module Manufacturer & 5.1 .5 .2 & \\
\hline B4.2 & Module Model & 5.1.5.2 & \\
\hline B4.3 & Active Material & 5.1.5.2 & \\
\hline B4.4 & Array Configuration & 5.1.5.2 & \\
\hline B4.5 & Array Maximum Power @ STC & 5.1 .5 .2 & 6.0 \\
\hline B4.6 & Array $V_{p p}$ & 5.1 .5 .2 & 6.0 \\
\hline B4.7 & Array $I_{p p}$ & 5.1 .5 .2 & 6.0 \\
\hline B4.8 & Array $\mathrm{V}_{\mathrm{oc}}$ & 5.1 .5 .2 & 6.0 \\
\hline B4.9 & Array $\mathrm{I}_{\mathrm{sc}}$ & 5.1 .5 .2 & 6.0 \\
\hline B4.10 & Array Shield & 5.1 .5 .2 & 5.2 .7 \\
\hline
\end{tabular}




\section{Stand-Alone Photovoltaic}

\section{System Summary - Page 2 of 2}

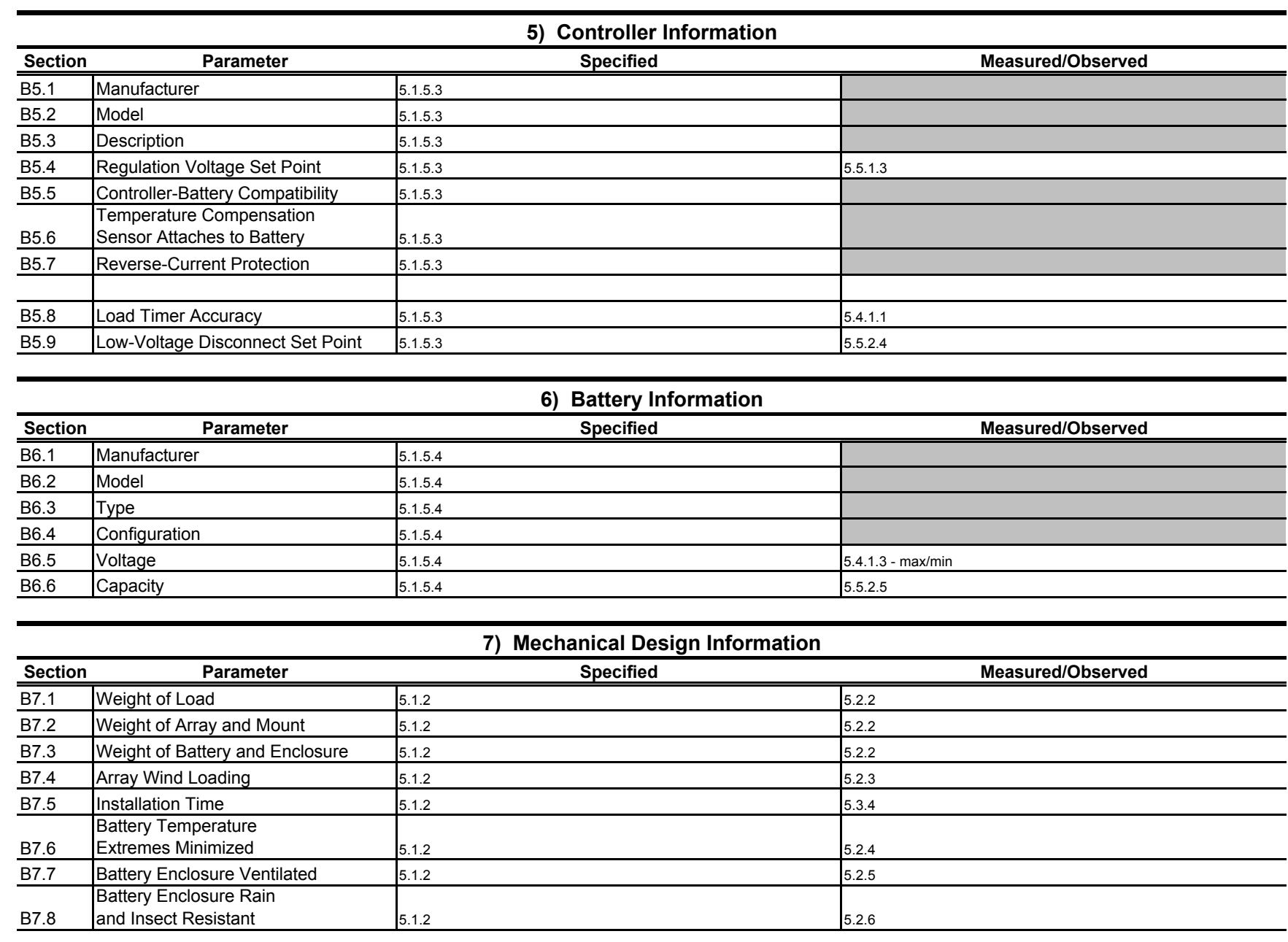

8) Documentation Checklist

\begin{tabular}{l|l|l|l}
\hline \multicolumn{1}{c|}{ Section } & \multicolumn{1}{c}{ Included } & \\
\hline \hline B8.1 & Parts List & 5.1 .1 & \\
\hline B8.2 & Required-But-Not-Included-Parts List & 5.1 .1 & \\
\hline B8.3 & Recommended-Tool List & 5.1 .1 & \\
\hline B8.4 & Mechanical Drawings & 5.1 .1 & \\
\hline B8.5 & Electrical Schematics & 5.1 .1 & \\
\hline B8.6 & Installation Procedures & 5.1 .1 & \\
\hline B8.7 & Spare-Parts List & 5.1 .1 & \\
\hline B8.8 & Maintenance Procedures & 5.1 .1 & \\
\hline B8.9 & Troubleshooting Guide & 5.1 .1 & \\
\hline B8.10 & Component-Specification Literature & 5.1 .1 & \\
\hline
\end{tabular}




\section{Annex B \\ (Informative) \\ Description of System Summary Terms and Parameters}

The numbers in parentheses indicate the corresponding test procedures section.

\section{B1 Test Information}

B1.1 Start Test Date (5.2.1)

The date the system arrived at the test facility.

B1.2 End Test Date (5.8.3)

The date of the final system inspection.

\section{B1.3 Report Date}

The date the System Summary is completed.

B1.4 Test Facility (5.1.2)

The name of the test facility.

B1.5 Address (5.1.2)

The address of the test facility.

B1.6 Contact (5.1.2)

The person in charge of conducting the testing.

\section{B2 System Information}

B2.1 Manufacturer (5.1.2)

The system manufacturer.

B2.2 Model (5.1.2)

The system model designation.

B2.3 Vendor (5.1.2)

The vendor selling the system.

\section{System Operation}

\section{B2.4 Run-Time (5.1.3, 5.4.1.1)}

The number of hours the load may operate each day/night.

\section{B2.5 Load Control Method (5.1.3)}

The method used to control the load. For example: automatic timer, manual switch, etc.

\section{B2.6 System Intended Location (5.1.3)}

The location where the PV system will actually be used, as opposed to the test location.

\section{B2.7 Intended Location Design Month (5.1.3, 5.4.2)}

This is the month where the A:L ratio is minimum, not necessarily the month with the minimum sun-hours. 


\section{System Performance Results}

\section{B2.8 Hours of Operation per Sun-Hour (5.1.4, 5.4.3)}

This value indicates that for every hour of sunlight how many hours you can expect the load to operate each day [9]. For example, if the Hours of Operation per Sun-Hour value were 2.0, and the average daily number of sun-hours for a particular location during a particular month were $5.0[5,8]$, then we could expect that the load could run for $2.0 \mathrm{x}$ 5.0 , or 10 hours per day.

$$
\text { Hours of Operation per Sun-Hour }=\frac{\text { ArrayEnergy Production }}{\text { LoadEnergyConsumption }},
$$

where

Array Energy Production (Ah) is the amp-hours received by the battery over the course of the Minimum A:L Ratio System Functional Test

Load Energy Consumption (Ah) is the amp-hours delivered to the load over the course of the Minimum A:L Ratio System Functional Test

\section{B2.9 Days of Autonomy (5.1.4, 5.5.3)}

This value indicates how long the system may operate the load during periods of low irradiance.

$$
\text { Days of Autonomy }=\frac{\text { TCBC }}{\text { Load Current x Daily Run - Time }},
$$

where

Battery Capacity (Ah) is the temperature corrected Ah capacity of the battery calculated. The UBC (5.5.2.4) is used if the battery-capacity temperature factor is not known.

Load Current (A) is the average current draw of the load.

Daily Run-time (Hrs/Day) is the number of hours the load is set to operate each day as recommended by the manufacturer.

\section{B2.10 Days to Battery Recovery (5.1.4, 5.6.4.5)}

The predicted number of average Design-Month days required to replace the UBC from the fully discharged battery with the load set for normal operation.

$$
\text { Days to Battery Recovery }=\frac{\text { TCBC }}{\text { DEBC }}
$$

where

$\underline{\mathrm{TCBC}}(\mathrm{Ah})$ is the temperature-corrected Ah capacity of the battery. The UBC (5.5.2.4) is used if the batterycapacity temperature factor is not known.

DEBC (Ah/Day) is the predicted charge from the array into the battery on an average Design-Month day for the intended location. 


\section{B3 Load Information}

\section{B3.1 Description (5.1.5.1)}

The type of load. For example: compact fluorescent lamp.

B3.2 Manufacturer (5.1.5.1)

The company that manufactures the load.

B3.3 Voltage (5.1.5.1, 5.4.1.1)

The load voltage.

B3.4 Current (5.1.5.1, 5.4.1.1)

The load current.

B3.5 Power (5.1.5.1, 5.4.1.1)

The load power.

B3.6 Operating Temperature Range (5.1.5.1)

The temperature range over which the load will start and operate.

B3.7 Number of Loads (5.1.5.1)

The number of loads being powered by the PV system. 


\section{B4 Array Information}

\section{B4.1 Photovoltaic Module Manufacturer (5.1.5.2)}

The manufacturer of the photovoltaic modules used in the array.

\section{B4.2 Module Model (5.1.5.2)}

The manufacturer's model designation for the module.

\section{B4.3 Active Material (5.1.5.2)}

The active material of the module. Some examples include single-crystalline silicon, polycrystalline silicon, and triple-junction amorphous silicon.

\section{B4.4 Array Configuration (5.1.5.2)}

The series and parallel configuration of the modules to form the array. For example, "2 series x 4 parallel."

B4.5 Array Pmax @ STC (5.1.5.2, 6.0)

The array output power at STC.

B4.6 Array $V_{p p}(5.1 .5 .2,6.0)$

The array voltage at maximum power.

\section{B4.7 Array $I_{p p}(5.1 .5 .2,6.0)$}

The array current at maximum power.

B4.8 Array $V_{\text {oc }}($ 5.1.5.2, 6.0)

The array open-circuit voltage at STC.

B4.9 Array $I_{\text {sc }}(5.1 .5 .2,6.0)$

The array short-circuit current at STC.

B4.10 Array Shield (5.1.5.2, 5.2.7)

A shield might be mounted on the backside, or in front of the modules to protect them from vandalism. If an array shield is used, the distance from the array and its construction shall be recorded. 


\section{B5 Controller Information}

\section{B5.1 Manufacturer (5.1.5.3)}

The company that manufactured the charge controller.

\section{B5.2 Model Number (5.1.5.3)}

The manufacturer's model designation for the charge controller.

\section{B5.3 Description (5.1.5.3)}

The type of controller: on/off, PWM, shunt, series, etc.

\section{B5.4 Regulation Voltage Set Point (5.1.5.3, 5.5.1.3)}

This is the highest voltage point to which the batteries are allowed to charge. Battery manufacturers specify the proper charge voltage that will lead to the optimum battery performance.

\section{B5.5 Controller/Battery Compatibility (5.1.5.3)}

The charge controller set-points need to be compatible with the battery type selected. Battery manufacturers specify the proper charge and discharge voltages that will lead to the optimum battery performance.

\section{B5.6 Temperature Compensation Sensor Attaches to Battery (5.1.5.3)}

Battery manufacturers recommend while charging a lead-acid battery, that the charge voltage varies slightly with battery temperature. The battery manufacturers recommend temperature compensated battery charging to ensure optimum battery performance. Temperature compensation is only effective if the battery temperature is sensed.

\section{B5.7 Reverse-Current Protection (5.1.5.3)}

This feature protects the system if the battery is connected backwards to the controller.

\section{B5.8 Load Timer Accuracy (5.1.5.3, 5.4.1.1)}

The accuracy of the timer. Inaccuracies in the load timer can lead to degraded system performance. A timer that runs much shorter than expected may annoy the user. A timer that allows the load to run too long could reduce the system's Days of Autonomy.

The load timer may be built into the load.

\section{B5.9 Low-Voltage Disconnect Set Point (5.1.5.3, 5.5.2.4)}

This is the lowest voltage point to which the batteries are allowed to discharge. Battery manufacturers specify the proper discharge voltage that will lead to the optimum battery performance.

The LVD circuitry may be built into the load. 


\section{B6 Battery}

\section{B6.1 Manufacturer (5.1.5.4)}

The manufacturer of the battery.

\section{B6.2 Model (5.1.5.4)}

The manufacturer's model designation for the battery.

\section{B6.3 Battery Type (5.1.5.4)}

Common lead-acid battery types found in PV systems include: flooded serviceable; flooded sealed; VRLA AGM; VRLA gel.

\section{B6.4 Battery Configuration (5.1.5.4)}

The series and parallel configuration of the individual batteries or cells used to make up the complete battery bank. For example, " 2 batteries in series x 2 parallel strings."

\section{B6.5 Voltage (5.1.5.4, 5.4.1.3)}

The voltage of the complete battery bank.

Due to the wide range of voltages that a battery in a PV system typically sees during charge and discharge, the measured maximum and minimum voltages are recorded here, rather than an average.

\section{B6.6 Capacity (5.1.5.4, 5.5.2.5)}

The battery capacity is the total amp-hours available from the complete battery bank. The rated value is normally provided by the battery manufacturer at the $\mathrm{C} / 20$ rate. The discharge rate should be recorded if other than $\mathrm{C} / 20$.

The measured value is determined from the fully charged battery when discharged by the load down to LVD. The measured value should be corrected for temperature. 


\section{B7 Mechanical Design}

\section{B7.1 Weight of Load (5.1.2, 5.2.2)}

The weight of the load and mounting structure.

B7.2 Weight of Array and Mount (5.1.2, 5.2.2)

The weight of the PV array, the mounting structure, and array back shield.

B7.3 Weight of Battery and Enclosure (5.1.2, 5.2.2)

The weight of all cells or batteries, and the enclosure.

\section{B7.4 Array Wind Loading (5.1.2, 5.2.3)}

The calculated wind loading equivalent to 120 -mph winds upon the array. This information can be helpful in determining if the fasteners are sufficient to connect the array to the pole. One can also determine if the pole can withstand the bending moment [9].

\section{B7.5 Installation Time (5.1.2, 5.3.4)}

The person-hours required to install the system using the manufacturer's installation instructions. For example, if the PV system took two people 2 hours to install, the person-hours would be $2 \times 2$, or 4 person-hours.

\section{B7.6 Battery Temperature Extremes Minimized (5.1.2, 5.2.4)}

Lead-acid battery capacity decreases as the battery temperature decreases. For this reason, it is important that the battery not be exposed to extreme temperatures. One method of achieving this is to bury the enclosure underground.

B7.7 Battery Enclosure Ventilated (5.1.2, 5.2.5)

Ventilation is important to avoid the buildup of explosive gases that are generated while the battery is charged.

B7.8 Enclosures Rain and Insect Resistant (5.1.2, 5.2.6)

Any enclosure openings should prevent water and insects from entering. 


\section{B8 Documentation Checklist}

\section{B8.1 Parts List (5.1.1)}

The list of parts that are included with the system.

B8.2 Required-But-Not-Included-Parts List (5.1.1)

The list of parts that are required to install the system, but that the user is required to provide.

\section{B8.3 Recommended Tool List (5.1.1)}

The list of tools required to install the system.

B8.4 Mechanical Drawings (5.1.1)

Detailed drawings used to facilitate system assembly.

\section{B8.5 Electrical Schematics (5.1.1)}

Complete electrical schematics that may include a one-line diagram and an electrical diagram that includes wire sizes, grounding techniques, fuse types, and switch ratings.

B8.6 Installation Procedures (5.1.1)

The procedures required to properly assemble the system.

\section{B8.7 Spare-Parts List (5.1.1)}

A list of recommended parts to keep on-hand to aid in the repair of the system, and where they can be purchased.

B8.8 Maintenance Procedures (5.1.1)

Routine maintenance procedures that should be performed on the system at regular intervals.

B8.9 Troubleshooting Guide (5.1.1)

A step-by-step guide to help the user determine what part of the PV system has failed.

B8.10 Component-Specification Data (5.1.1)

Detailed documentation for each major component. 


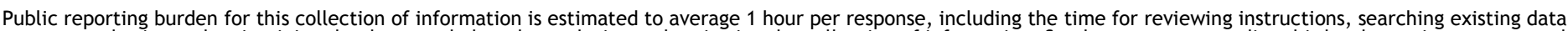

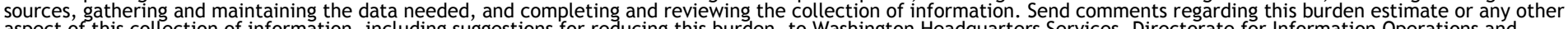

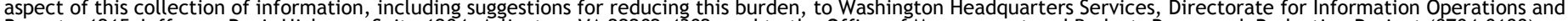

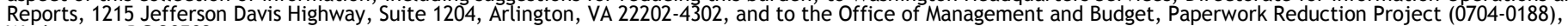
Washington, DC 20503.
1. AGENCY USE ONLY (Leave blank)
2. REPORT DATE September 1999
3. REPORT TYPE AND DATES COVERED
Technical Report

4. TITLE AND SUBTITLE

Procedures for Determining the Performance of Stand-Alone Photovoltaic Systems

6. AUTHOR(S)

P. McNutt, B. Kroposki, R. Hansen, R. DeBlasio, M. Thomas, S. Durand, A. Rosenthal, and

P. Hutchinson

7. PERFORMING ORGANIZATION NAME(S) AND ADDRESS(ES)

9. SPONSORING/MONITORING AGENCY NAME(S) AND ADDRESS(ES)

National Renewable Energy Laboratory

1617 Cole Blvd.

Golden, CO 80401-3393

$\mathrm{C}:$

TA: PV907301

8. PERFORMING ORGANIZATION REPORT NUMBER

10. SPONSORING/MONITORING AGENCY REPORT NUMBER

TP-520-27031

11. SUPPLEMENTARY NOTES

12a. DISTRIBUTION/AVAILABILITY STATEMENT

National Technical Information Service

U.S. Department of Commerce

5285 Port Royal Road

Springfield, VA 22161

13. ABSTRACT (Maximum 200 words)

This document provides the procedures for determining the performance of stand-alone PV systems. The procedures in this document provide a common approach for evaluating whether a given PV system is suitable to perform the function for which it was designed and manufactured to accomplish, and whether it will provide adequate power to run the load. These procedures cover small stand-alone PV systems. They cover complete outdoor system testing. Test results are valid only for the system that is tested.

14. SUBJECT TERMS

photovoltaics ; stand-alone photovoltaic systems ; test procedures ; testing methodology ;

system inspection

17. SECURITY CLASSIFICATION
OF REPORT
Unclassified

18. SECURITY CLASSIFICATION OF THIS PAGE Unclassified
15. NUMBER OF PAGES

16. PRICE CODE

20. LIMITATION OF ABSTRACT

UL 